UCRL-JC-125790

PREPRINT

\title{
BBU Design of Linear Induction Accelerator Cells for Radiography Application
}

\author{
C. C. Shang, Y.-J. Chen, G. J. Caporaso, T. L. Houck \\ N. E. Molau, S. D. Nelson \\ LLNL \\ J. Fockler, PSI
}

S. Gregory, Bechtel Nevada

This paper was prepared for submittal to the

1997 Particle Accelerator Conference

Vancouver, BC, Canada

May 12-16, 1997

May 6, 1997

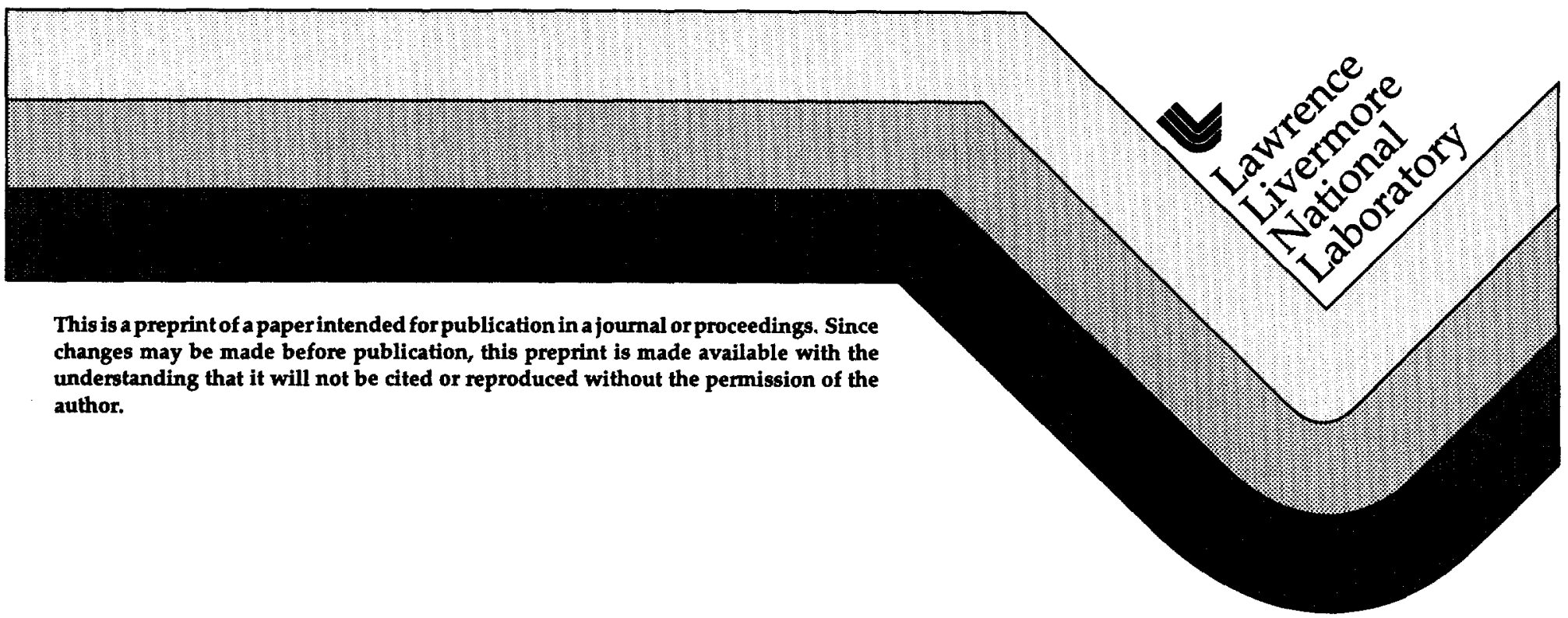




\section{DISCLAIMER}

This document was prepared as an account of work sponsored by an agency of the United States Government. Neither the United States Government nor the University of California nor any of their employees, makes any warranty, express or implied, or assumes any legal liability or responsibility for the accuracy, completeness, or usefulness of any information, apparatus, product, or process disclosed, or represents that its use would not infringe privately owned rights. Reference herein to any specific commercial products, process, or service by trade name, trademark, manufacturer, or otherwise, does not necessarily constitute or imply its endorsement, recommendation, or favoring by the United States Government or the University of California. The views and opinions of authors expressed herein do not necessarily state or reflect those of the United States Government or the University of California, and shall not be used for advertising or product endorsement purposes.

This work was supported by the U.S. Department of Energy, Nevada Operations Office, under Contract No. DE-AC08-96NV11118.

By acceptance of this article, the publisher and/or recipient acknowledges the right of the US. government to retain a nonexclusive, royalty-free license in and to any copyright covering the article. 


\title{
BBU DESIGN OF LINEAR INDUCTION ACCELERATOR CELLS FOR RADIOGRAPHY APPLICATION'
}

\author{
C. C. Shang, Y.-J. Chen, G. J. Caporaso, T. L. Houck, N. E. Molau, S. D. Nelson, and W. C. Ng \\ Lawrence Livermore National Laboratory
}

J. Fockler, PSI

S. Gregory, Bechtel Nevada

\section{Abstract}

There is an ongoing effort to develop accelerating modules for high-current electron accelerators for advanced radiography application. Accelerating modules with low beam-cavity coupling impedances along with gap designs with acceptable field stresses comprise a set of fundamental design criteria. We examine improved cell designs which have been developed for accelerator application in several radiographic operating regimes. We evaluate interaction impedances, analyze the effects of beam structure coupling on beam dynamics (beam breakup instability and corkscrew motion). We also provide estimates of coupling through interesting new highgradient insulators and evaluate their potential future application in induction cells.

\section{INTRODUCTION}

The nature of the electromagnetic interaction of a charged particle beam in an accelerator beampipe with imperfections or perturbations in the beampipe wall is of fundamental importance to the design of an induction accelerator. These interactions can be characterized by an interaction impedance, which relates moments of the beam current to the work done on the beam by the beam-induced electromagnetic fields. The impedance quantities of interest may all be derived from the characteristic wake potential W, defined by the expression

$$
\begin{gathered}
\mathbf{W}(s)=\frac{1}{Q} \int_{-\infty}^{\infty} d z(\mathbf{E}+\mathbf{v} \times \mathbf{B})_{\mid v z=s+z} \\
\mathbf{Z}_{t}(\omega)=\frac{j}{v} \int_{-\infty}^{\infty} \mathbf{W}_{t}(s) e^{j k s} d s
\end{gathered}
$$

Over the past fifteen years, several high current linear induction cells have been built and tested. One of the fundamental design objectives is to minimize the transverse dipole coupling impedance since the growth rate of beam breakup instability (BBU) is proportional to the transverse coupling impedance. A form factor,

$$
\eta=\left(Z, b^{2}\right) /(4 w c)
$$

where $b$ is the beampipe radius and $w$ is the gap width, is a figure of merit from the viewpoint of BBU. $\eta$ is tabulated in Figure 1 for existing cells in addition to new

\begin{tabular}{|c|c|c|c|c|c|c|}
\hline Cell & \begin{tabular}{|c|}
$\begin{array}{c}\text { Beampipe } \\
\text { radius }\end{array}$ \\
\end{tabular} & Gap & \begin{tabular}{|c|} 
BBU \\
frequency
\end{tabular} & $\begin{array}{l}\text { Trans } \\
\text { imped }\end{array}$ & \begin{tabular}{|l|} 
Form \\
factor
\end{tabular} & Chara \\
\hline & $7.41 \mathrm{~cm}$ & n & $816 \mathrm{MHz}$ & $\begin{array}{c}670 \\
\text { ohms/meter }\end{array}$ & 1.6 & \\
\hline ETA-II & & & & $\begin{array}{c}700 \\
\text { ohms/meter }\end{array}$ & 1.7 & BBU rings \\
\hline FX & & & & & 1.9 & \\
\hline ATA & $\mathrm{m}$ & & 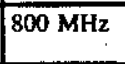 & & 1.4 & \\
\hline & 7 & & & $\begin{array}{c}490 \\
\text { ohms/meter }\end{array}$ & 1.1 & \\
\hline FXR/U & $7.3 \mathrm{c}$ & $5 \mathrm{~cm}$ & $350 \mathrm{MHz}$ & $\begin{array}{c}1000 \\
\text { ohms/meter }\end{array}$ & 1.3 & $\begin{array}{l}\text { Two cell } \\
\text { types }\end{array}$ \\
\hline
\end{tabular}
cell designs for advanced radiography including DARHT, and FXR-upgrade.

Figure 1. Table of induction cell form factors for existing and new induction cell designs.

\section{WAKEFIELD ANALYSIS}

There are several features characterizing existing linear induction accelerator (LIA) cell design. Characteristic in several designs is the presence of a shielded gap. The purpose of the shielded gap design is to provide an RF filter effect for BBU modes, in addition to preventing direct line of sight between beam and insulator. Another conventional approach involves application of comer reflectors comprising either of lossy ferrite or highly conducting electric materials. These design features have also been successfully employed to both damp and direct wakefields towards lossy induction core material.

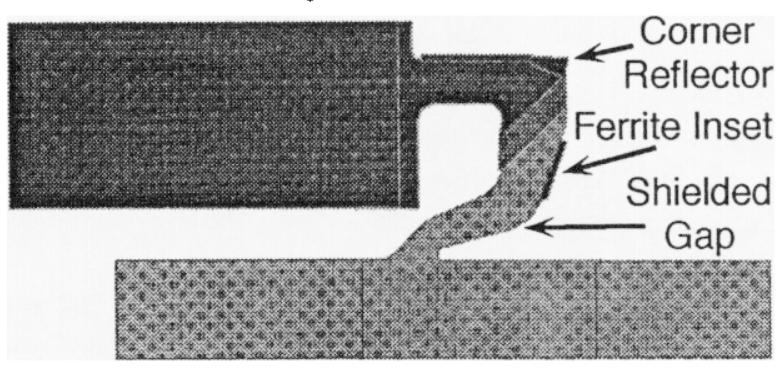

Figure 2. DARHT-2 short pulse design with ferrite inset.

Several new improvements in induction cell design hold the promise for additional suppression of beam break-up modes. Recently, we have examined the use of ferrite insets on the vacuum side of the insulator in

\footnotetext{
1 This work was performed under the auspices of the U.S. Department of Energy by the Lawrence Livermore National Laboratory under Contract No. W-7405-Eng-48.
} 
designs for DARHT (Fig. 2) and AHF. The ferrite inset geometry must be designed to minimize field enhancement over the field stresses in the unperturbed cavity structure. Typical inset designs can be optimized for minimal field enhancement and recent work on DARHT-2 short pulse design has maximum field enhancements over the unperturbed case of $27 \%$. Another key consideration is to ensure that the damping ferrites are positioned on the anode electrode to avoid possible difficulties with field induced emission.

\section{DAMPING FERRITE}

A key requirement for accurate impedance calculations is highly realistic material data. Data for two well-known ferrites in the LIA community are the TDK PE11b [2] and TDK PE16. We measured the magnetic dispersion characteristics of PE16 (Fig. 3). We found that in the VHF to L-band microwave spectrum, it is more lossy than TDK PE1lb. In impedance calculations, the difference is manifested as a 5-10\% reduction in transverse impedance. Small differences in phase due to the thickness of the ferrite sample cause the fine structure (non-physical) in the data.

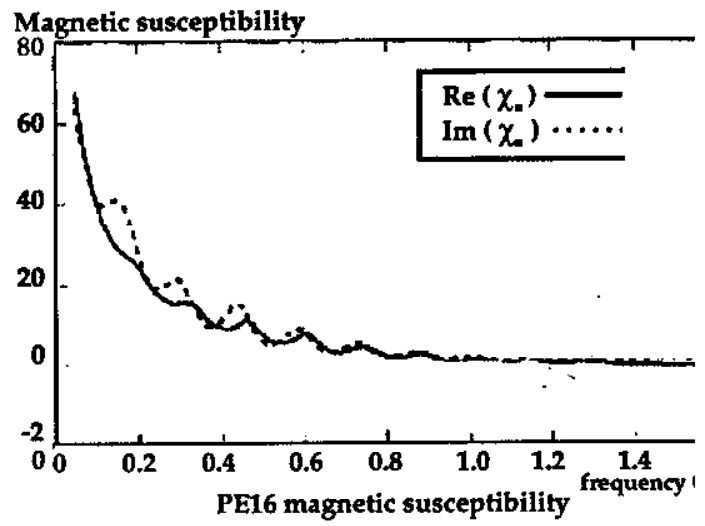

Figure 3. Magnetic dispersion for PE-16 ferrite material

\section{CELL DESIGN}

For two cell designs (DARHT short pulse and FXRupgrade) the ferrite insets are employed. For the DARHT2 design, a DARHT-1-like cell employing corner reflector yields an impedance spectrum with two BBU resonances. $(\sim 270 \mathrm{MHz}$ and $\sim 750 \mathrm{MHz})$

The utilization of the ferrite inset on the vacuum side obtains a low-Q spectrum in Fig. 4. We found that placement of ferrite nearer to the gap yields this desirable frequency impedance dependence. We have also examined its application at FXR. For FXR, we see a similar effect in that we have a nominal impedance with conventional design featuring a BBU resonance at $800 \mathrm{MHz}$. Calculations using the damping ferrite insets on the vacuum side also obtains a low- $Q$ impedance spectrum which we found for the DARHT-2 short pulse design. Wakefield calculations predict an upgraded FXR cell with $\eta=1.3$ (Fig. 5). Impedance measurements at FXR are currently in progress.

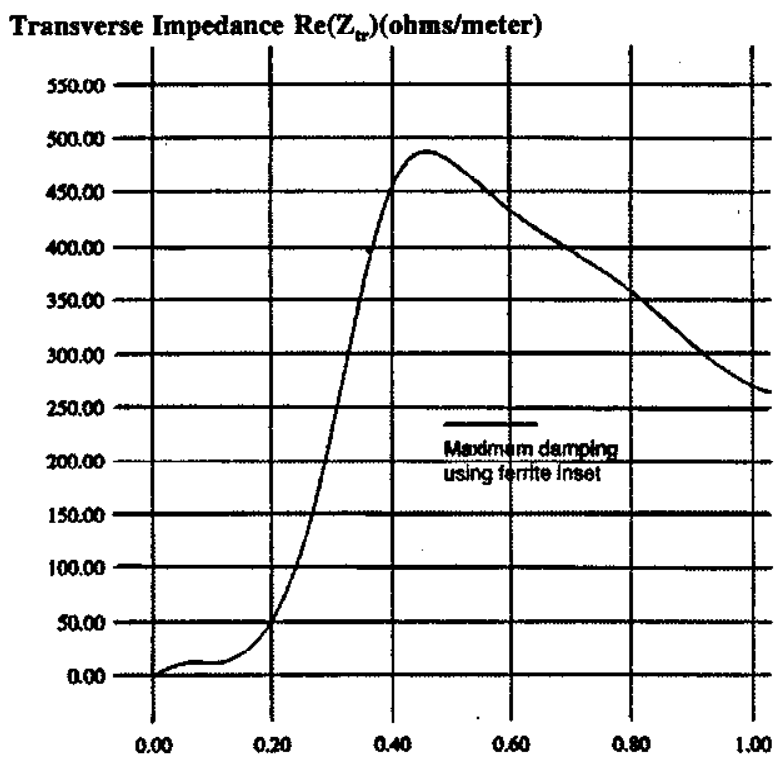

Frequency (GHz)

Figure 4. DARHT-2 short pulse dipole impedance spectrum with $\eta=1.1$

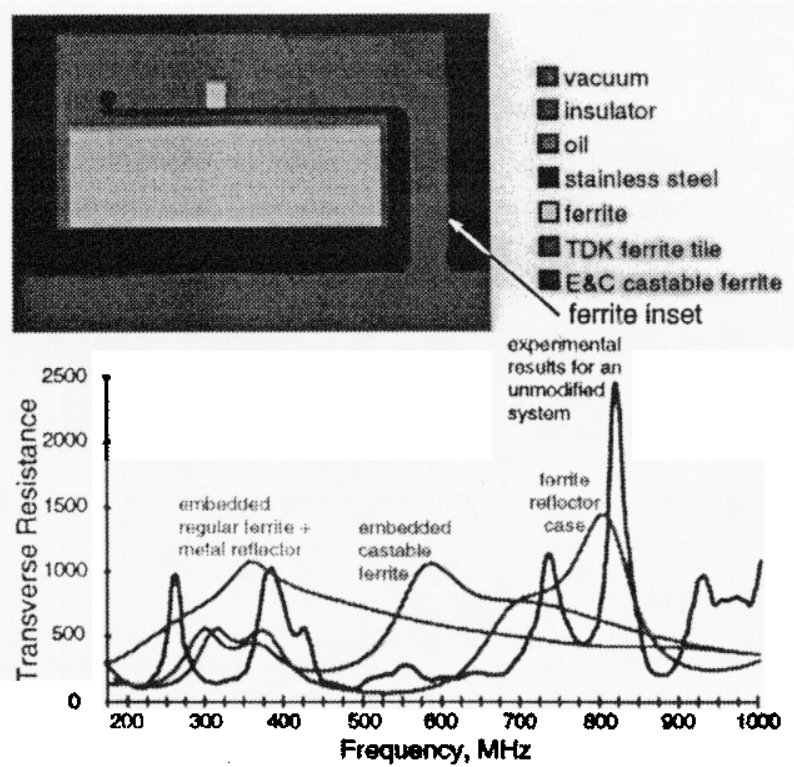

Figure 5. Computed impedance spectrum for FXR cell upgrade

\section{BEAM DYNAMICS SIMULATIONS}

Simulations of the beam breakup instability are required to evaluate the low- $Q$ impedance spectrum characteristic of ferrite insets. The DARHT-2 short pulse configuration is similar to DARHT-1 except the cell and solenoid parameters are changed. The injected beam into the accelerator is at $4 \mathrm{MeV}$ and $4 \mathrm{kA}$. The magnetic tune averaged at $700 \mathrm{G}$ is chosen so that a beam with a 190 mm-mrad normalized edge emittance [3] is focused gently from $4.6 \mathrm{~cm}$ radius to about $0.6 \mathrm{~cm}$ radius within the first 7.5 meters, and is maintained at $0.6 \mathrm{~cm}$ radius through the rest of the machine. 
In the simulations, the beam breakup instability is driven by misalignment of magnets. The DARHT-1 alignment specification [4] is used in the simulations. The $3-\sigma$ of random magnet tilts and random magnet offsets is $1.95 \mathrm{mrad}$ and $0.45 \mathrm{~mm}$, respectively. We assume that the injector and the induction cell voltages have $15 \mathrm{~ns}$ rise time and $70 \mathrm{~ns}$ flat-top with a small linear ramp. These voltage ramps introduce an $\pm 1 \%$ energy variation to the beams, and hence corkscrew motion. Without any steering, the peak-to-peak (p-p) BBU amplitude and the corkscrew amplitude is $4 \mathrm{~mm}$ and $3 \mathrm{~mm}$, respectively. Assume that beam position monitors are located between cell-blocks, and their resolution is $0.1 \mathrm{~mm}$. We minimize the corkscrew amplitude by using the corkscrew tuning curve algorithm [5] and the averaged centroid displacement at alternating beam position monitors. We found that both the beam breakup instability and corkscrew motion are controllable with steering as shown in Fig. 6. The BBU only appears in the first $10 \mathrm{~ns}$ of the flat-top portion of the pulse, and its p-p amplitude at the end of accelerator is $1.2 \mathrm{~mm}$. The corkscrew amplitude is $0.6 \mathrm{~mm}$. Note that the magnetic tune used in the simulation is relatively weak. Nevertheless, both the simulated BBU amplitude and corkscrew amplitude are small enough to satisfy the final focus requirement .

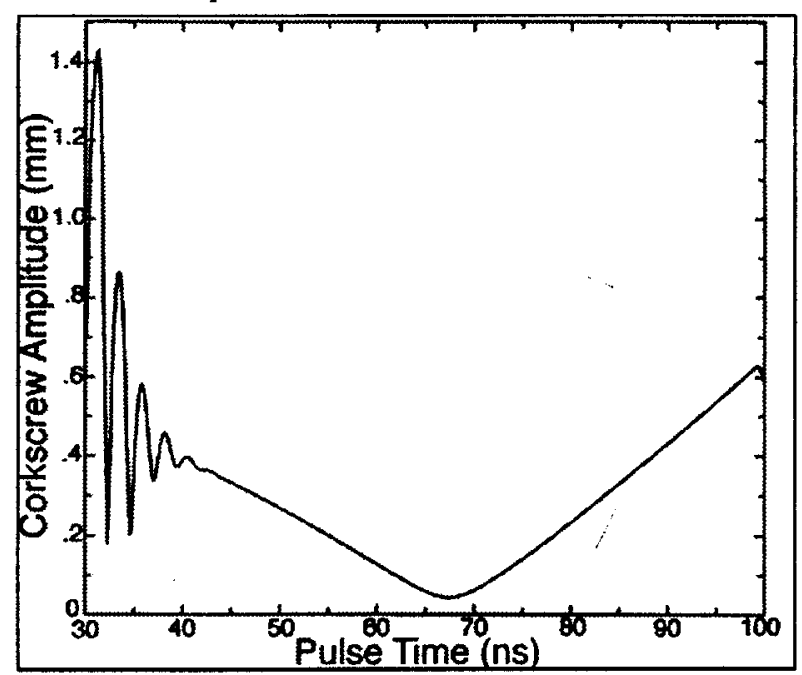

Figure 6. BBU and corkscrew motion at the end of the DARHT-2 accelerator for the short pulse option

\section{HIGH GRADIENT INSULATOR STRUCTURE}

It has been reported that a high gradient insulator structure, consisting of a periodic structure of alternating conductor and dielectric has voltage hold-off properties of up to 5 times conventional insulator technology [6]. In recent impedance experiments [7] it was shown that the impedance value has a strong dependence on dielectric-tometal thickness ratio. Suitability for induction cell application also requires evaluation of the radial length and position of the insulator in the gap and its effect on impedance. In Fig. 7 , by varying radial length and position we observe that a further reduction in the interaction impedance is achievable. The effect appears to be mode dependent.

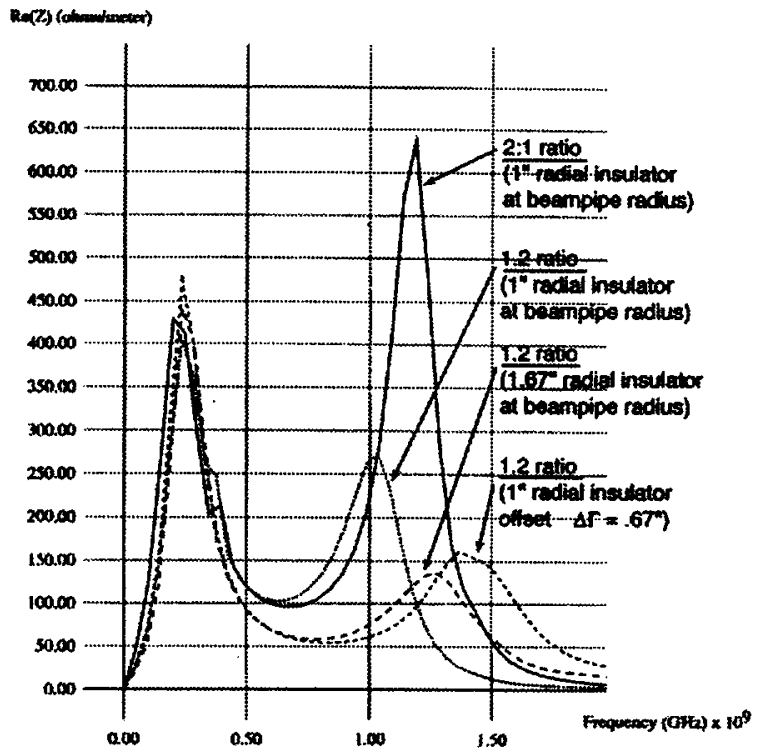

Figure 7. High gradient insulator structure in damped pillbox with $\mathrm{ID}=5.75^{\prime}, \mathrm{OD}=10^{\prime \prime}$, and gap $=1 "$

\section{CONCLUSION}

Future induction accelerator designs may profit from new improvements involving ferrite damping materials and insulators to help achieve very low impedance structures with possibly more robust insulator performance. Experiments at FXR and AHF design and test activities are underway.

\section{ACKNOWLEDGMENT}

Stimulating discussions with J. Melton, J. Carlson, and J. Downing at LANL and G. Westenskow LLNL are gratefully acknowledged. We express appreciation to $\mathrm{D}$. Prono and M. Burns at LANL, and R. E. Clough, LLNL, for their encouragement and support.

\section{REFERENCES}

[1] R. J. Briggs, et al, "Theoretical and Experimental Investigation of the Interaction Impedances and $Q$ Values of the Accelerating Cells in the Advanced Test Accelerator," Particle Accelerators, 1985, Vol. 18.

[2] J. DeFord and G. Kamin, "Application of Linear Magnetic Loss Model of Ferrite to Induction Cavity Simulation," 1990 Linear Accelerator Conf., Sept. 1990, pp 384-386.

[3] T. P. Hughes, private communication.

[4] M. J. Burns, private communication.

[5] Yu-Jiuan Chen, "Control of Transverse Motion Caused by Chromatic Aberration and Mis-alignments in Linear Accelerators", to be published in Nucl. Inst. Methods in Phys. Res. A.

[6] S. Sampayan, et al, "High Performance Insulator Structures for Accelerator Applications," these proceedings.

[7] T. Houck, et al, "Measured and Theoretical Characterization of the RF Properties of Stacked, High Gradient Insulator Material," these proceedings. 


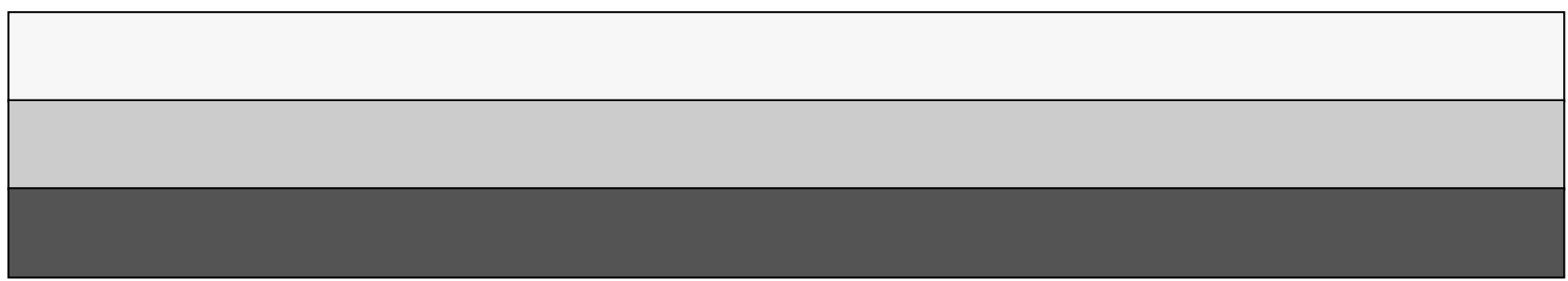

